\title{
LA FAMILIA CRISTIANA EDUCADORA DE LA FE EN ALGUNOS DOCUMENTOS ECLESIASTICOS RECIENTES
}

\author{
Antonio Arza Arteaga, s.j.
}

La familia recibe muchas denominaciones. Pío XI la denominaba una verdadera sociedad más antigua que cualquier otra, regida por una autoridad propia, es decir, la paterna. Otros la llaman «el más firme principio del orden en la vida social». Cauce sagrado de la vida humana, especie de Iglesia doméstica, raíz de la sociedad humana, germen primero de la sociedad, origen y fundamento de la sociedad civil, fuente primera y necesaria de la sociedad humana, fundamento de la sociedad civil, la célula más perfecta y fecunda de la sociedad.

Haciendo siempre referencia a la sociedad civil se la considera como fundamento de la misma y como su célula vital, siendo la raíz natural y fecunda de la grandeza y potencia de la nación. Pío XII repite muchas veces que la familia es uno de los elementos fundamentales, una de «las líneas esenciales del orden natural».

Con todo ello, no encontramos en los documentos eclesiásticos una definición, ni descriptiva, de la familia, con una característica peculiar: que casi todos los documentos empiezan describiendo las características y los defectos de la familia, partiendo del concepto vulgar vigente de la misma.

Es comprensible que los documentos no quieran dar una definición de la familia, porque ésta es una institución compleja y está sujeta cada momento a cambios importantes que de un momento a otro la pueden modificar en sus elementos no esenciales.

Tampoco hemos encontrado una definición propiamente tal de la familia cristiana, como tal, aunque ésta es más fácilmente descriptible indicando que es la familia donde se profesa la religión cristiana. Pero aún en esto hay graves problemas. ¿Es necesario que todos los miembros de la familia profesen la religión católica, para que se pueda decir la familia cristiana? ¿O basta que la profesen sólo algunos de los miembros? ¿Es 
familia cristiana aquella en la que los padres profesan la religión cristiana, aunque los hijos no la profesen o practiquen?

Como se ve, el concepto mismo de la familia cristiana es un concepto impreciso. Por eso, para entender lo que debe ser la familia cristiana, portadora de la fe, como diremos después ad intra o ad extra, vamos a transcribir lo que dice el Papa Pío XII en forma descriptiva de lo que debe ser la familia cristiana. «¿Qué más feliz, qué más placentero sobre la tierra que la familia cristiana? Nace ante el altar del Señor, donde el amor es declarado vínculo santo y perpetuamente duradero, se consolida y crece con ese mismo amor nutrido por la gracia divina. En ella el matrimonio es para todos honorable e inmaculado el tálamo conyugal (Heb. 13,4). Las tranquilas paredes de la casa no resuenan con el alboroto de las desavenencias, ni son testigos del secreto martirio al revelarse las taimadas insidias de la infidelidad; la sólida confianza mantiene alejados los aguijones de la sospecha; con el mutuo afecto de la benevolencia se mitigan los dolores y se acrecientan las alegrías. En ella, los hijos no son considerados como carga, sino como dulces prendas, ni hay torpes razones de comodidad o prurito de placeres estériles que lleven a impedir el don de la vida o a que se desconozca el dulce nombre de hermanos o hermanas. Con cuánto afán procuran ahí los padres que los hijos crezcan vigorosos y, siguiendo las huellas de sus mayores, cuyo recuerdo mantienen siempre presente, resplandezcan con una purísima fe y honestidad de costumbres. Movidos por tantos beneficios, consideren los hijos que su principal obligación es la de honrar a sus padres, obedecer sus mandatos, prestarles seguro auxilio en sus años seniles, alegrar su vejez con un amor que no rompe la muerte, sino que se hará más vigoroso y más pleno en el cielo. Los miembros de una familia cristiana, ni quejumbrosos en la adversidad ni ingratos en las horas felices, confían siempre en Dios, a cuyo imperio obedecen, en cuya voluntad confían, cuya ayuda no esperan en vano.» ${ }^{1}$

Si realmente se da una familia de esta naturaleza y en ella se dan todos estos aspectos positivos de la vida es imposible que no prolongue a los miembros de la misma familia y aun otras familias esa felicidad, fruto de la fe. Familias como éstas tienen que ser necesariamente portadoras de la fe dentro de los miembros de la familia y para con las demás familias y personas con las que están en contacto. Porque no pueden menos de compartir esa felicidad que nace de su fe y amor que nacidos del Sacramento del Matrimonio se han desarrollado en el ejercicio y práctica de la fe y el amor cristianos.

\footnotetext{
1 Pío XII, Sertum laetitiae, n. 8.
} 
El Concilio Vaticano II ha trazado también una imagen de la familia cristiana, similar a la descrita por el Papa Pío XII: «Gracias a los padres, que precederán con el ejemplo y la oración en la familia, hijos, y aún los demás que viven en el círculo familiar, encontrarán más fácilmente el camino del sentido humano, de la salvación y de la santidad. En cuanto a los esposos, ennoblecidos por la dignidad y la función de padre y madre, realizarán concienzudamente el deber de la educación, principalmente la religiosa, que a ellos, sobre todo compete. Los hijos como miembros vivos de la familia, contribuyen, a su manera, a la santificación de los padres, pues con el agradecimiento, la piedad filial y la confianza corresponderán a los beneficios recibidos de sus padres, y, como hijos, los asistirán en las dificultades de la existencia y en la soledad de la senectud. La viudez, continuidad de la vocación conyugal, aceptada con fortaleza de ánimo, será honrada por todos. La familia hará partícipes a otra, generosamente, de sus riquezas espirituales. Así es como la familia cristiana, cuyo origen está en el matrimonio que es imagen y participación de la alianza del amor entre Cristo y la Iglesia, manifestará a todos la presencia viva del Salvador en el mundo y la auténtica naturaleza de la Iglesia, ya por el amor, la generosa fecundidad, la unidad y fidelidad de los esposos, ya por la cooperación amorosa de todos sus miembros.» ${ }^{2}$

Si realmente la familia cristiana tiene todas estas cualidades es lógico que sea educadora de la fe de sus miembros y, que su acción evangelizadora se extienda también más allá de sus propios límites naturales. Pero no vamos a sacar conclusiones, sino recoger unos documentos en los cuales las autoridades eclesiásticas afirmen que la familia es educadora de la fe.

Pero antes de seguir adelante vamos a indicar una cuestión que puede surgir en la inteligencia de algunos de estos documentos. En efecto, algunos documentos hablan de la familia en un doble plano cuando hablan en general de la familia educadora, como de la familia educadora de la fe. Indican en algunos casos que la familia equivale en estos casos a los padres a quienes incumbe la educación de los hijos, sobre todo, cuando se trata de la educación en general y de la educación en la fe en particular de hijos muy jóvenes. En otros casos, sin embargo, hablan de la familia como comunidad de vida y amor compuesta de padres e hijos como educadora de la fe, tanto ad intra de la familia, como ad extra de la misma. Conviene tener en cuenta este dato para entender el contenido de algunos documentos.

\footnotetext{
2 Gaudium et Spes, n. 48.
} 


\section{EI Concilio Vaticano II}

Como la extensión del artículo no permite alargarnos demasiado vamos a ceñirnos a documentos eclesiásticos recientes. Y, en primer lugar, vamos a empezar por el Concilio Vaticano II.

En efecto, este Concilio habla con frecuencia de la obligación de los padres de educar a los hijos. Pero no contento con esto, habla repetidas veces de la educación en la fe de los hijos y la acción evangelizadora de la familia. Al hablar del ejercicio del sacerdocio común de los fieles en los sacramentos, refiriéndose a los cónyuges cristianos dice: «Finalmente los cónyuges cristianos, en virtud del Sacramento del Matrimonio por el que significan y participan en el misterio de unidad y amor fecundo entre Cristo y la Iglesia, (Eph. 5,32) se ayudan mutuamente a santificarse en la vida conyugal y en la procreación y educación de la prole, y por eso poseen su propio don, dentro del pueblo de Dios en su estado y forma de vida. De este consorcio procede la familia, en la que nacen nuevos ciudadanos de la sociedad humana, quienes por la gracia del Espíritu Santo, quedan constituidos en el Bautismo hijos de Dios. En esta especie de Iglesia doméstica los padres deben ser para los hijos los primeros predicadores de la fe, mediante la palabra y el ejemplo, y deben fomentar la vocación propia de cada uno, pero con un cuidado especial, la vocación sagrada.» ${ }^{3}$

En el texto aparece implícita y explícitamente que los padres son para los hijos los primeros predicadores de la fe. En efecto, si la familia es como una Iglesia doméstica no cabe duda de que en esa Iglesia debe haber una predicación de la fe. Y naturalmente esta predicación comprende a toda la familia, pues toda ella constituye la Iglesia doméstica. Pero no se contenta con indicar de forma metafórica esa obligación que incumbe a la familia, sino que explícitamente dice que los padres son para los hijos los primeros predicadores de la fe. Como decíamos arriba, el Concilio entiende que los padres constituyen en la infancia de los niños la parte consciente y responsable de la familia y por ello impone a los mismos la obligación de ser los predicadores de la fe. Y, además, los primeros predicadores.

Esta predicación deben ejercerla los padres con la palabra y el ejemplo. De aquí se deduce la obligación que tienen los padres de estar informados en materia de la doctrina de la Iglesia para poder impartirla a sus hijos desde la más tierna infancia y el ejemplo que deben dar en su vida, conformándola con el contenido de la fe.

\footnotetext{
3 Lumen gentium, n. 11.
} 
Hablando de este testimonio de vida de los laicos, dice el Concilio: «En esta tarea (es decir, el anuncio de Cristo por el testimonio de la vida y de la palabra) resalta el gran valor de aquel estado de vida satificado por especial sacramento, a saber, la vida matrimonial y familiar. En ella el apostolado de los laicos halla una ocasión de ejercicio y una escuela preclara, si la religión cristiana penetra toda la organización de la vida y la transforma más cada día. Aquí los cónyuges tienen su propia vocación: el ser mutuamente y para sus hijos testigos de fe y amor de Cristo. La familia cristiana proclama en voz muy alta tanto las presentes virtudes del Reino de Dios como la esperanza de la vida bienaventurada. De tal manera, con su ejemplo arguye al mundo de pecado e ilumina a los que buscan la verdad.» ${ }^{4}$ La familia es testigo de la fe y del amor de Cristo y con ello es la auténtica educadora y portadora de la fe tanto ad intra, dentro de la familia, como ad extra, hacia todos aquellos con los que se pone en contacto.

2. Pero no sólo en la Constitución «Lumen Gentium» ha hablado el Concilio de la misión educadora de la fe de la familia, sino que también en otros documentos ha resaltado esta función de la familia cristiana como una de sus características fundamentales. En el Decreto «Apostolicam actuositatem» vuelve a recordar la importancia del apostolado de la familia como educadora de la fe: «El Creador del mundo estableció la sociedad conyugal como origen y fundamento de la sociedad humana. Con su gracia la convirtió en sacramento grande de Cristo y en la Iglesia (Eph. 5,32). Por ello, el apostolado de los esposos y las familias tiene singular importancia, tanto para la Iglesia como para la sociedad.» ${ }^{5}$

Al ponderar el apostolado de las familias indudablemente las supone a éstas como portadoras de la fe, porque el apostolado en la Iglesia no tiene otro sentido que el llevar la fe y demás contenido cristiano a aquellos que se evangeliza. Pero no se contenta con una expresión general de la importancia del apostolado, sino que indica a continuación el contenido de éste: «Los esposos cristianos son para sí mismos, para sus hijos y demás familiares, cooperadores de la gracia y testigos de la fe. Son para sus hijos los primeros predicadores y educadores de la fe, los forman con su palabra y ejemplo para la vida cristiana y apostólica, les ayudan prudentemente a elegir su vocación y fomentan con todo esmero la vocación sagrada cuando la descubren en los hijos.. ${ }^{6}$

No cabe duda que en la mente del Concilio la familia es la portadora de la educación en la fe de manera especial para los hijos, para los cuales

${ }^{4}$ Ibídem, n. 35; cf. n. 41.

5 Apostolicam Actuositatem, n. 11.

${ }^{6}$ Ibídem. 
los padres son los primeros predicadores y educadores de la misma. A continuación, describe lo que debe constituir una parte importante de su apostolado no sólo en relación con los hijos, sino también con respeto a todas aquellas personas a las que llega su acción. Pero volviendo de nuevo a la misión fundamental de la familia dice: «La familia ha recibido directamente de Dios la misión de ser la cédula primera y vital de la sociedad. Cumplirá esta misión, si por la mutua piedad de sus miembros y la oración en común dirigida a Dios se ofrece como santuario doméstico de la Iglesia; si la familia entera se incorpora al culto litúrgico de la Iglesia; si finalmente la familia practica el ejercicio de la hospitalidad y promueve la justicia y demás obras buenas al servicio de todos los hermanos que padecen necesidad.» ${ }^{7}$

Y, finalmente, describe las diferentes obras de apostolado que puede realizar la familia: «Entre las diferentes obras de apostolado familiar pueden mencionarse las siguientes: adoptar como hijos a niños abandonados, acoger con benignidad a los forasteros, colaborar en la dirección de las escuelas, asistir a los jóvenes con consejos y ayudas económicas, ayudar a los novios a prepararse mejor para el matrimonio, colaborar en la catequesis, sostener a los esposos y a las familias que están en peligro material o moral, proveer a los ancianos no sólo de lo indispensable, sino también de los justos beneficios del desarrollo económico.» ${ }^{8}$

Y, por último, exalta el ejemplo que dan las familias cristianas en sitios donde acaba de empezar la predicación del Evagelio, o la Iglesia se encuentra en sus comienzos o en algún grave peligro9.

Como medio para realizar este apostolado indica que las familias pueden reunirse en asociaciones familiares ${ }^{10}$.

En el mismo Decreto, el Concilio indica que los padres y los educadores cristianos deben formar a sus hijos y a los jóvenes para el apostolado, enseñándoles a preocuparse, con su ejemplo, de las necesidades del prójimo, tanto materiales como espirituales: «Toda familia y su vida en común sean, pues, como iniciación al apostolado.» ${ }^{11}$

3. No queremos dejar de indicar, aunque sea brevemente, otros dos documentos en los que se indica que las familias son las educadoras de la fe de sus hijos. Así en la Declaración «Dignitatis humanae», dice: «Cada familia, en cuanto sociedad que goza de un derecho propio y primordial, tiene derecho a ordenar libremente su vida religiosa doméstica bajo la di-

\footnotetext{
7 Ibídem.

8 Ibídem.

9 Ibídem.

${ }^{10}$ Ibídem.

${ }^{11}$ Apostolicam Actuositatem, n. 30.
} 
rección de los padres. A éstos corresponde el derecho de determinar la forma de educación religiosa que se ha de dar a los hijos de acuerdo con su propia convicción religiosa.» ${ }^{12} \mathrm{Y}$ añade a continuación que la autoridad civil debe respetar este derecho de los padres, respetando el derecho de elección de la escuela y otros medios de educación que ellos quieran, sin imponerles cargas injustas por esta elección.

4. En la declaración sobre la educación cristiana de la juventud hace resaltar la grave obligación que tienen los padres de educar a sus hijos por haberles dado la vida; por ello los padres son los primeros educadores de los hijos. Pero al describir qué familia deben crear los padres viene a indicar claramente que los padres son los educadores de la fe de sus hijos: «Es, pues, deber de los padres crear un ambiente de familia animado por el amor, por la piedad hacia Dios y hacia los hombres, que favorezca la educación íntegra personal y social de los hijos. La familia es, por lo tanto, la primera escuela de las virtudes sociales que todas las sociedades necesitan. Sobre todo en la familia cristiana, enriquecida por la gracia y los deberes del Sacramento del Matrimonio, importa que los hijos aprendan desde los primeros años a conocer y adorar a Dios y amar al prójimo según la fe recibida en el Bautismo. Encuentren en la familia la primera experiencia de una saludable sociedad humana y de la Iglesia. Por medio de la familia, en fin, se introducen fácilmente en la sociedad civil y en el Pueblo de Dios. Consideren, pues, la importancia que tiene la familia verdaderamente cristiana para la vida y el progreso del mismo Pueblo de Dios.» ${ }^{13}$

A pesar de que el Concilio Vaticano II no promulgó ningún documento directamente relacionado con la familia, sin embargo, en los documentos dio un valor fundamental a todo el contenido de la familia y dentro de ésta a su vocación de educadora de la fe tanto dentro de la familia, como hacia afuera, siendo realmente una Iglesia doméstica con todas las funciones que la Iglesia tiene en orden a la formación y santificación de los fieles.

III

\section{Paulo VI}

De los Papas posteriores al Concilio, vamos a recoger un documento importante de Paulo VI y varios de Juan Pablo II.

12 Dignitatis humanae, n. 5.

13 Gravissimun educationis, n. 3. 
Paulo VI, en su Exhortación Apostolica «Evangelii nuntiandi», tiene un testimonio realmente esclarecedor de la función evangelizadora de la familia. Hablando de los agentes de la Evangelización enumera entre ellos a la familia. En el seno del apostolado evangelizador de los seglares es imposible dejar de subrayar la acción evangelizadora de la familia, porque es «Iglesia doméstica» en expresión del Vaticano II y, por eso en ella deberán reflejarse los diversos aspectos de la Iglesia y debe ser un espacio donde es transmitido el Evangelio y desde donde éste se irradia: «En el seno del apostolado evangelizador de los seglares es imposible dejar de subrayar la acción evangelizadora de la familia. Ella ha merecido muy bien, en diferentes momentos de la historia y en el Concilio Vaticano II, el hermoso nombre de «Iglesia doméstica». Esto significa que, en cada familia cristiana, deberían reflejarse los diversos aspectos de la Iglesia entera. Por otra parte, la familia, al igual que la Iglesia, debe ser un espacio donde el Evangelio es transmitido y desde donde éste se irradia.

Dentro, pues, de una familia consciente de esta misión, todos los miembros de la misma evangelizan y son evangelizados. Los padres no sólo comunican a los hijos el Evangelio, sino que pueden a su vez recibir de ellos este mismo Evangelio profundamente vivido. También las familias formadas por un matrimonio mixto tienen el deber de anunciar a Cristo a los hijos en plenitud de las implicaciones del bautismo común; tienen además la no fácil tarea de hacerse artífices de la unidad.

Una familia así se hace evangelizadora de otras muchas familias y del ambiente en que ella vive ${ }^{14}$.

No se puede expresar con más claridad la doble función de educadora de la fe que tiene la familia cristiana, es decir, la función de educar a los miembros de la familia, tanto los padres a los hijos como éstos a los padres en la fe, siendo evangelizadora; $y$, al mismo tiempo, ser evangelizadora de las demás familias y del ambiente en que viven.

Se puede también indicar que Paulo VI en su Encíclica «Humanae vitae» habla del testimonio que deben dar los esposos para realizar su vocación delante de todo el mundo, con lo que les convierte en educadores de la fe de otros ${ }^{15}$. Y añade: «Una nueva e importantísima forma de apostolado entre semejantes se inserta de este modo en el amplio cuadro de la vocación de los laicos: los mismos esposos se convierten en guía de otros esposos. Esta es, sin duda, entre las numerosas formas de apostolado una de las que hoy aparecen más oportunas.» ${ }^{16}$

\footnotetext{
14 Paulo VI, Evangelii nuntiandi, n. 71.

15 Paulo VI, Humanae vitae, n. 15.

16 Ibídem, n. 26.
} 
Se pueden citar algunos discursos del Papa Paulo VI a grupos de matrimonios en los que les indica su función educadora de la fe de los hijos y aun de otros matrimonios en la línea del «Evangelii nuntiandi». Pero lo dejamos de lado para no alargarnos demasiado, porque aún nos quedan muchos documentos que tenemos que citar.

\section{IV}

\section{Juan Pablo II}

El Papa Juan Pablo II ha hablado y escrito mucho sobre la familia y sus funciones. Vamos a recoger algunas citas de sus textos, sin querer ser exhaustivos.

En su Exhortación Apostólica «Familiaris consortio», dice sobre la función educadora de la fe de los padres: «En la medida en que la familia cristiana acoge el Evangelio y madura en la fe, se hace comunidad evangelizadora. Escuchemos de nuevo a Paulo VI (y cita el texto que arriba hemos transcrito). Como ha repetido el Sínodo, recogiendo mi llamada lanzada en Puebla, la futura evangelización depende en gran parte de la Iglesia doméstica. Esta misión apostólica de la familia está enraizada en el Bautismo y recibe con la gracia sacramental del matrimonio una nueva fuerza para transmitir la fe, para santificar y transformar la sociedad actual según el plan de Dios.

La familia cristiana, hoy sobre todo, tiene una especial vocación a ser testigo de la alianza pascual de Cristo, mediante la constante irradiación de la alegría del amor y la certeza de la esperanza de la que debe dar razón. «La familia cristiana proclama en voz alta tanto las presentes virtudes del Reino de Dios como la esperanza de la vida bienaventurada.» (L.G. 35).

La absoluta necesidad de la catequesis familiar surge con singular fuerza en determinadas situaciones que la Iglesia constata por desgracia en diversos lugares. En los lugares donde una legislación antirreligiosa pretende incluso impedir la educación en la fe o donde ha cundido la incredulidad o ha penetrado el secularismo hasta el punto de resultar prácticamente imposible una verdadera creencia religiosa, la Iglesia doméstica es el único ámbito donde los niños y los jóvenes pueden recibir una auténtica catequesis ${ }^{17}$.

17 Juan Pablo II, Familiaris consortio, n. 62; Vaticano II, Gravissimum educationis, n. 3; Catechesi tradendae, n. 36. 
En otro párrafo el Papa pondera la educación de los hijos en la oración: «Sobre todo en la familia cristiana enriquecida con la gracia y los deberes del Sacramento del Matrimonio importa que los hijos aprendan desde los primeros años a conocer y adorar a Dios y amar al prójimo según la fe recibida en el Bautismo.» ${ }^{18}$

Indica a continuación que el elemento esencial para una buena educación a la oración es el ejemplo de los padres y cita unas palabras de una alocución de Paulo VI en la que pregunta a los padres si en las diversas circunstancias de la vida enseñan a sus hijos a recurrir a la oración y recabar la ayuda de la Virgen y de los santos ${ }^{19}$.

Al hablar de la familia como la primera, aunque no única, comunidad educadora concluye el Papa «que debe asegurarse absolutamente el derecho de los padres a la elección de una educación conforme con su fe religiosa $»^{20}$. Esto quiere decir que los padres tienen el derecho y, por lo tanto, el deber de dar una educación religiosa, y si son familias cristianas una educación en la fe, que es base de la vida cristiana.

Comparando a la familia cristiana con la Iglesia, dice el Papa que la familia participa de la misión de la Iglesia: «Por su parte, la familia cristiana está inserta de tal forma en el misterio de la Iglesia, que participa, a su manera, en la misión de la salvación que es propia de la Iglesia. Los cónyuges y los padres cristianos, en virtud del sacramento, «poseen su propio don dentro del pueblo en su forma y estado de vida» (L.G. 11). Por eso no sólo reciben el amor de Cristo, convirtiéndose en comunidad salvada, sino que están también llamados a transmitir a los hermanos el mismo amor de Cristo, haciéndose así comunidad salvadora. De esta manera, a la vez que es fruto y signo de la fecundidad sobrenatural de la Iglesia, la familia cristiana se hace símbolo, testimonio y participación de la maternidad de la Iglesia.» ${ }^{21}$

Esto quiere decir que así como la Iglesia es educadora de la fe, la familia cristiana es también educadora como Ella de esa misma fe, tanto en relación con los hijos, como con otros hermanos, siendo una comunidad salvadora.

Podíamos citar más testimonios de esta exhortación del Papa, pero vamos a dejarlos por razón de la extensión del trabajo para aducir otros testimonios del Papa y otros documentos.

Sin embargo, antes de terminar lo referente a la Exhortación «Familiaris consortio», tenemos que añadir que todo el contenido referente a

\footnotetext{
18 Juan Pablo II, o.c., n. 60.

19 Juan Pablo II, Ibídem.

20 Juan Pablo II, Ibídem, n. 40.

21 Juan Pablo II, Ibídem, n. 49.
} 
los sacramentos, matrimonio, penitencia, y la plegaria familiar, maestros de oración, plegaria litúrgica y privada (nn. 56-61) tiene un fondo del contenido de la familia cristiana educadora de la fe, porque todos esos actos son unos medios por los que se educa en la fe a los cónyuges entre sí y a los hijos y todos aquellos hasta los que llega la irradiación de todos esos actos de la familia cristiana.

La familia cristiana, comunidad al servicio del hombre (nn. 63-64) es también aplicable a la misión educadora de la familia en la fe, porque su misión es educar a los miembros de la familia y a todos los hombres en el amor y descubrir en el hombre la imagen de Dios. Indudablemente, todo esto es un contenido de la fe: «Otro cometido de la familia cristiana es la de formar los hombres en el amor y practicar el amor en toda relación humana con los demás, de tal modo que ella no se encierre en sí misma, sino que permanezca abierta a la comunidad, inspirándose en un sentido de justicia y solicitud hacia los otros, consciente de la propia responsabilidad hacia toda la sociedad. ${ }^{22}$

2. El Papa Juan Pablo II en su Exhortación Apostólica «Christifieles laici» aborda también la función educadora de la familia en la fe. Aborda el problema desde el aspecto de la evangelización y de la catequesis y afirma que los padres son los primeros catequistas de los hijos: «Los padres cristianos son, desde luego, los primeros e insustituibles catequistas de sus hijos, habilitados para ello por el Sacramento del Matrimonio; pero, al mismo tiempo, todos debemos ser conscientes del "derecho" que todo bautizado tiene de ser instruido, educado, acompañado en la fe y en la vida cristiana. ${ }^{23}$

En esta nueva evangelización, para la evangelización hacen falta evangelizadores. Y el Papa recurre a las familias cristianas como los primeros evangelizadores: «Para la evangelización del mundo hacen falta evangelizadores. Por eso, todos, comenzando por las familias cristianas, debemos sentir la responsabilidad de favorecer el surgir y madurar vocaciones específicamente misioneras, ya sacerdotales y religiosas, ya laicales, recurriendo a todo medio oportuno, sin abandonar jamás el medio privilegiado de la oración, según las mismas palabras del Señor Jesús: La mies es mucha y los obreros pocos. Pues, ;rogad al dueño de la mies que envíe obreros a su mies!» (Mt. 9,37-38) ${ }^{24}$

3. Se puede afirmar que el Papa Juan Pablo II recurre a esta función educadora de la fe de la familia tanto en sus Exhortaciones, como en discursos dirigidos a familias y a esposos. En la Exhortación «Catechesi tra-

22 Juan Pablo II, Ibídem, n. 64.

23 Juan Pablo II, Christifideles laici, n. 34.

24 Juan Pablo II, Ibídem, n. 34. 
dendae» habla largamente de la cuestión. No vamos a transcribir todo, sino solamente indicar algunos puntos principales: «La acción catequética de la familia tiene un carácter peculiar y en cierto sentido insustituible, subrayado con razón por la Iglesia, especialmente en el Concilio Vaticano II.» ${ }^{25}$ Pero no sólo indica este carácter de su peculiaridad y de su imposible sustitución, sino que además indica cómo se verifica esta misión educadora de la fe en la familia: «Esta educación en la fe, impartida por los padres — que de comenzar desde la más tierna edad de los niños - se realiza ya cuando los miembros de la familia se ayudan unos a otros a crecer en la fe por medio de su testimonio de vida cristiana, a menudo silencioso, más perseverante a lo largo de una existencia cotidiana, vivida según el Evangelio.» ${ }^{26}$.

Indica después la forma de transmitir las verdades de la fe al ritmo de los acontecimientos familiares, recepción de sacramentos, celebración de fiestas litúrgicas, el nacimiento de un hijo, o la causa de luto, procurando explicar el contenido de estos acontecimientos. Esta forma de transmisión de las verdades de la fe dejará en los niños una huella indeleble y para toda la vida. Y los padres hacen en éstos un esfuerzo peculiar que les proporciona un bien especial, porque en este diálogo catequético cada uno recibe y $\mathrm{da}^{27}$.

La catequesis familiar precede y acompaña a todas las demás catequesis. Allí donde la actitud antirreligiosa impide la educación religiosa, esta catequesis familiar es la única que realmente da a los niños y a los jóvenes la única educación religiosa ${ }^{28}$.

Para este ministerio los padres deben prepararse constantemente, no sólo para ser catequistas de sus hijos, sino también para el ejercicio del celo infatigable. Es necesario alentar a las personas y a las instituciones para que con toda clase de medios ayuden a los padres a esta formación ${ }^{29}$.

4. No podemos dejar de citar a modo de ejemplo alguno de los innumerables discursos en los cuales el Papa ha hablado de la familia como educadora de la fe. Pero al no poder citar muchos discursos, nos vamos a fijar en dos, en uno de los cuales habla el Papa de que los padres son los primeros educadores de sus hijos y otro en que habla de una familia cristiana y su cometido apostólico.

a) «Vosotros, padres, sois y debéis ser los primeros y fundamentales educadores de vuestros hijos, engendrando en el amor y por amor nuevas

\footnotetext{
25 Catechesi tradendae, AAS. 71 (1979), pp. 227 ss.

26 Ibídem.

27 Ibídem.

28 Ibídem.

29 Ibídem.
} 
personas, asumís la tarea de ayudarlos eficazmente a vivir una vida plenamente humana y cristiana. La familia es la primera escuela de virtudes humanas y sociales, de que tienen necesidad, hoy especialmente, todas las estructuras civiles y políticas. Educar a los hijos en los valores esenciales de la vida, en el sentido de la verdadera justicia, del auténtico honor, del respeto de la propia y ajena dignidad, pero más aún en el sentido del verdadero amor, como solicitud y servicio desinteresado hacia los otros, en particular los más pobres y necesitados.»

Educar a los hijos en los grandes valores de la fe cristiana: en la fe en Dios Padre, en Cristo, su Hijo, en el Espíritu Santo. «La primera escuela de catequesis es y debe ser la familia. Del padre, de la madre, de los hermanos y hermanas mayores deben recibir los niños - junto con los ejemplos de la vida cristiana - el testimonio de las grandes verdades de la revelación divina, que luego profundizarán en la catequesis orgánica en las parroquias, en los institutos, en los movimientos.» ${ }^{30}$

No sólo deben educar, por decirlo así, en la teoría de la fe, sino también en la práctica: «Pero, sobre todo, vosotros, padres, debéis educar a vuestros hijos en la plegaria, introducirlos en el descubrimiento progresivo del misterio de Dios y en el coloquio personal con El. Esta oración hecha en familia, que es la Iglesia doméstica, constituye para los hijos la introducción natural a la oración litúrgica propia de toda la iglesia. Es necesaria, por tanto, una progresiva participación de todos los miembros de la familia en la Eucaristía dominical y festiva, y en los otros sacramentos, en especial, los de la iniciación cristiana.» ${ }^{31}$

b) En un discurso a los obispos alemanes sobre evangelización, refiriéndose a la familia, dice el Papa: «Cuando hablamos de evangelización, debemos pensar sobre todo en la familia cristiana: la célula originaria de toda sociedad humana prevista por el orden de la creación es también el primer lugar para la adquisición de la fe. La familia es el lugar del encuentro de las generaciones; en ella han de aprenderse las virtudes sociales; en el intercambio cotidiano la fe viene a ser una experiencia personal y al mismo tiempo comunitaria. El cuidado de las almas debe por ello mirar a reforzar la familia, a protegerla de la amenaza de tendencias adversas y a guiarla al cometido apostólico en cuanto realidad madura.» ${ }^{32}$

5. No debemos dejar de citar el mensaje cuaresmal de este año, que por ser el año de la familia, lo titula: «La familia está al servicio de la ca-

\footnotetext{
${ }^{30}$ Juan Pablo II, Encuentro con las familias en Foggia. En Familia cristiana en la enseñanza de Juan Pablo II, p. 13.

${ }^{31}$ Juan Pablo II, Ibídem.

32 Juan Pablo II, Discurso a los obispos alemanes, Roma, 23-I-1988. En Familia cristiana, p. 153.
} 
ridad y la caridad al servicio de la familia.» ${ }^{33}$ El Papa insiste en el aspecto de la ayuda caritativa que la familia debe dar, sobre todo, a los más necesitados. Pero para eso, es necesario que la familia esté enraizada en la fe y en el amor: «La familia es el primer lugar privilegiado de la educación y de ejercicio de la vida fraterna, de la caridad y de la solidaridad, cuyas formas son múltiples. En las relaciones familiares se aprenden la atención, la acogida y el respeto del otro, que debe tener siempre en nuestro corazón aquel puesto que le pertenece.» $\mathrm{Y}$ exhorta a todos el Papa a compartir con los demás, sobre todo, con los más necesitados con una solidaridad sin fin.

Aunque el mensaje va dirigido a todas las familias, no se puede negar que desde su titulación un llamamiento a la conciencia de las familias cristianas. Todo el mensaje es una llamada a la solidaridad y a la prestación de la ayuda a familias necesitadas.

Podríamos seguir recogiendo la misma idea de la familia educadora de la fe en diversos escritos, discursos y mensajes del Papa Juan Pablo II. Pero lo dejamos para otro momento, porque el espacio nos impide seguir recogiendo más textos del Papa.

\section{V}

\section{La Conferencia Episcopal española}

1. La Comisión Episcopal para la Doctrina de la Fe el 7 de mayo de 1977 dio una instrucción sobre «La estabilidad del matrimonio». En esta instrucción hay una expresión realmente iluminadora de la mente de la Conferencia Episcopal sobre la familia educadora de la fe, pero no sólo de los propios hijos, sino de todas las personas que les rodean. Hablando de la renovación de los esposos cristianos afirma que los esposos no sólo deben interesarse de la propia renovación espiritual, sino que su fe tiene que ser siempre un impulso evangelizador. Y después de indicar que la fe predicada con el testimonio de la propia vida dentro de las comunes condiciones del mundo afirma: «Las familias cristianas deben sentirse responsables del testimonio de la fe que la Iglesia debe dar, a través de ellas en el mundo de hoy. Han de ser apóstoles de las otras familias.» ${ }^{34}$

2. Pero donde la Conferencia Episcopal ha expuesto ampliamente este pensamiento de la familia educadora de la fe es en la Instrucción «Matrimonio y Familia». Hace una descripción de todo el contenido de

\footnotetext{
33 L'Osservatore Romano, 2 de febrero de 1994.

${ }^{34}$ Conferencia Episcopal española, La estabilidad del matrimonio, n. 29.
} 
la familia como «Iglesia doméstica». Toda comunidad cristiana es convocada por una palabra de Dios, que la envía con la misión de proclamar la proximidad del Reino: «Esto mismo podemos afirmar de la familia Iglesia doméstica.» También ella ha sido convocada por la palabra de Dios y recibe, como Iglesia, el encargo de anunciar primero dentro de la familia misma; pero también hacia afuera, en el propio ambiente. Lo comunitario, en este caso la familia, puede expresar más plenamente el testimonio cristiano. Por eso, el Concilio sitúa preferentemente en el nivel familiar la misión testimonial del cristiano seglar: «La familia cristiana proclama con voz muy alta tanto las presentes virtudes del Reino de Dios como la esperanza de la vida bienaventurada.» (L.G.n. 35) ${ }^{35}$

No cabe duda de que la Conferencia Episcopal considera a la familia como una enviada con la misión de proclamar el Reino tanto dentro como fuera de la propia familia; lo que quiere decir que la considera como educadora de la fe de la misma familia y de otras familias.

Pero, como veremos más adelante, no sólo lo dice deductivamente, sino que lo proclama abiertamente. En efecto, después de una descripción de lo que es la comunidad familiar, dedica una extensa exposición a la familia, como fuente de vida cristiana: «La familia cristiana está llamada a ser lugar de privilegio de vivencia de una fe compartida por todos sus miembros. Los padres, verdaderos creyentes saben que la transmisión de la fe a sus hijos no puede reducirse a la enseñanza de una doctrina, ni a una praxis moral, ni de unas obligaciones religiosas. Ha de ser, sobre todo, su propia vivencia de la fe la que sirve de testimonio que suscite y eduque la fe de sus hijos.» ${ }^{36}$

Explica a continuación que la familia cristiana ha de ser comunidad de oración, una comunidad eclesial que participa en la celebración de los sacramentos y, por último, la familia ha de ser una realidad esencialmente misionera.

Describe después que la familia es escuela de valores evangélicos, el amor cristiano, que nace de Dios y va más allá del mero respeto a las personas. La pobreza y la austeridad, porque como las bienaventuranzas han de ser objeto constante de la reflexión de la comunidad familiar. La justicia y la verdad, porque vivimos en una sociedad en la que prevalecen la injusticia, la ambición y la fuerza de los menos escrupulosos que no tienen en cuenta la moralidad de los medios. La paz y la comprensión, creando un ambiente familiar en el que se destierre toda violencia y se aprenda a vivir el mensaje de Jesús. Y, por fin, el diálogo y el respeto, en una constante comunicación de pareceres y en un respeto de la verdad de cada uno, sabiendo escuchar y respetar todas las personas.

35 Ibídem, n. 51.

36 Ibídem, n. 58. 
Una familia en la que se haga todo esto es esencialmente portadora de la fe y sus contenidos a todos los miembros de la misma ${ }^{37}$.

No contenta con todo esto, la Conferencia dice explícitamente que la Iglesia considera a los padres como los primeros evangelizadores de los hijos y, por eso, los padres y las madres deben ser los primeros educadores de la fe: «La Iglesia considera a los padres como los primeros evangelizadores de sus hijos» y administra el Bautismo a los niños «en la Iglesia» bajo el compromiso de padres y padrinos de transmitirles el mensaje de Jesús. Por eso, los padres y las madres deben ser los primeros educadores de la fe (el subrayado es nuestro); y aun cuando en muchos casos carezcan de la preparación pedagógica que sería de desear, siempre podrán comunicar a sus hijos, con su palabra y su testimonio, las actitudes religiosas básicas, confianza en Dios Padre, amor a Jesucristo Salvador, docilidad a los impulsos del Espíritu, devoción a la Virgen María, sentido del pecado, apertura a todos los hombres, conciencia de Iglesia...

«Por otra parte, nadie más indicado que los propios padres para introducir a sus hijos en la comunidad parroquial, donde éstos podrán completar la catequesis e ir dando los pasos sacramentales que corresponden a su nivel de edad y de maduración cristiana. Esto obliga a los mayores a no desmentir con su conducta y con el estilo de vida familiar, lo que los niños van descubriendo en la experiencia catequética. Aquí radican no pocas crisis de la práctica religiosa y de la misma fe personal de adolescentes y jóvenes.» ${ }^{38}$

No es necesario hacer ningún comentario para demostrar que según la Conferencia Episcopal la familia es portadora de la fe y la primera portadora, transmitiéndola a sus hijos sea de palabra sea de obra siendo en su conducta consecuentes con el contenido de la fe que les han transmitido.

3. Con motivo del Año Internacional de la Familia, la Conferencia publicó una nota en la que viene a reafirmar su doctrina expuesta en la Instrucción que hemos examinado más arriba. Afirma primero la Conferencia que es muy grande la importancia que tiene la familia para el bienestar y correcto progreso de la sociedad, porque la familia es «la escuela del más rico humanismo» (G.S.n. 52), así como el deterioro de la vida familiar suscita ordinariamente el deterioro de la vida social y de los valores comunitarios.

A continuación, expone la importancia de la familia en la vida de la Iglesia. A través de ella nos insertamos en la Iglesia por las aguas del Bautismo. En el primer templo en que aprendemos a orar, un lugar privi-

\footnotetext{
37 Ibídem, nn. 62-67.

38 Ibídem, n. 73.
} 
legiado de formación y evangelización, la primera escuela de solidaridad y de servicio recíproco y el punto de partida de nuestras experiencias comunitarias. (F.C. 21). Ella es la «Iglesia doméstica» y la primera escuela de vida cristiana» en la que se aprende la paciencia, el gozo del trabajo, el amor fraterno, el perdón generoso, incluso reiterado y, sobre todo, el culto divino por medio de la oración y la ofrenda de sí mismo» (Cat. de la I.C.n. 1657; cfr. L.G.nn. 10, 11).

Esto parece que bastaría para decir que la familia es educadora de la fe. Pero, por si no bastara, los obispos lo declaran abiertamente: «A la familia y, en particular, a los padres, está encomendado, como honroso derecho y sagrado deber, la misión educadora. Ella es la primera responsable y la protagonista de la educación de los hijos y con ella ha de colaborar, sin suplantarla, tanto el Estado como la Iglesia.» ${ }^{39}$ A ella corresponde la educación integral de los hijos, luego también su educación religiosa.

\section{VI}

\section{La Conferencia Episcopal italiana}

Unas breves palabras, porque el espacio no nos permite alargarnos, sobre la misión educadora de la familia en su Directorio de la Pastoral familiar. Después de exponer su misión como comunidad evangelizadora y la forma de ejercer su misión habla de la educación de los hijos y afirma que cumple su misión evangelizadora en su interior, es decir, en las relaciones de padres e hijos. «En efecto, los cónyuges cristianos son cooperadores de la gracia y testigos de la fe recíprocamente y ante los hijos y todos los demás familiares. Son los primeros pregoneros de la fe y educadores de sus hijos; les forman para la vida cristiana y apostólica con la palabra y con el ejemplo, les ayudan con prudencia en la elección de su vocación y favorecen, con toda diligencia, la sagrada vocación descubierta en ellos.

«Este misterio de evangelización de los padres cristianos no es más que la consecuencia lógica y natural dimensión de la exigencia educativa inscrita en su ser de progenitores. La relación educativa originaria que, en virtud de la generación les vincula a los hijos exige, efectivamente, que los progenitores respeten y promuevan plenamente la identidad personal, social y eclesial de los hijos. En esta perspectiva su trabajo educativo tiene como fin irrenunciable de cada uno de los hijos como miembros vitales de

39 Nota con motivo del Año Internacional de la Familia. B.O. del Obispado de Santander, diciembre de 1993, p. 43. 
la Iglesia de Cristo.»40 Y al explicar esta función educadora dice: «Sean para ellos los primeros maestros de la fe, porque desde la más tierna edad les enseñen a percibir el sentido de Dios y venerarlo y a ver al prójimo según la fe que han recibido en el Bautismo.» ${ }^{41}$ Expone, a continuación, cómo deben seguir la vida de los hijos y acompañarles en la preparación de la recepción de los sacramentos, de la iniciación cristiana, cómo deben completar la catequesis vivida en la parroquia, etc.

Por fin, indican que la catequesis familiar debe preceder, acompañar y enriquecer cualquier otra catequesis; debe haber un diálogo sobre la fe en la familia, pero, sobre todo, se debe vivir según el Evangelio los acontecimientos de la vida, tanto ordinarios, como extraordinarios.

Señalan la importancia que pueden tener ciertos signos visibles de la fe en la casa, como un crucifijo, un libro de Sagrada Escritura, la oración antes y después de las comidas, etc.

\section{VII}

\section{El Catecismo de la Iglesia Católica}

Por su carácter especial, hemos dejado para el último lugar al Catecismo de la Iglesia Católica y el Código de Derecho Canónico. El Catecismo recoge la misión educadora de la fe en la familia fundamentalmente en la exposición del cuarto mandamiento entre los deberes de los padres (nn. 2225-2229), aunque también toca el asunto en otros puntos, como por ejemplo, en el n. 1657, en el que habla de la familia como «Iglesia doméstica», y la primera escuela de vida cristiana.

Al hablar de los deberes de los padres, dice: «Por la gracia del Sacramento del Matrimonio, los padres han recibido la responsabilidad y el privilegio de evangelizar a sus hijos. Desde la primera edad, deberán iniciarlos en los misterios de la fe de los que ellos son para sus hijos los "primeros heraldos de la fe". Desde la más tierna infancia deben asociarlos a la vida de la Iglesia.» ${ }^{42}$ Los padres han recibido esta responsabilidad por la gracia del matrimonio.

Esta educación en la fe debe empezar desde la más tierna infancia: «La educación en la fe por los padres debe comenzar desde la más tierna infancia. Esta educación se hace ya cuando los miembros de la familia se ayudan a crecer en la fe mediante el testimonio de una vida cristiana de

\footnotetext{
40 Conferenza Episcopale italiana, Direttorio di pastorale familiare, n. 143.

41 Ibídem, n. 144.

42 Catecismo de la Iglesia Católica, n. 2225.
} 
acuerdo con el Evangelio. La catequesis familiar precede, acompaña y enriquece las otras formas de la enseñanza de la fe. Los padres tienen la misión de enseñar a sus hijos a orar y a descubrir su vocación de hijos de Dios.» (cf. L.G. 11) ${ }^{43}$

Pero no sólo los padres deben dar esta educación a los hijos, sino que los hijos deben también ayudar a los padres: «Los hijos a su vez contribuyen al crecimiento de sus padres en la santidad (cf. Ct n. 48,4). Todos y cada uno deben otorgarse generosamente y sin cansarse el mutuo perdón exigido por las ofensas, las querellas, las injusticias y las omisiones. El afecto mutuo lo sugiere. La caridad de Cristo lo exige. ${ }^{44}$

Por último, añade que los padres, como los primeros responsables de la educación de los hijos, tienen derecho a exigir y elegir para ellos una escuela que corresponda a sus propias convicciones. Y este derecho es un derecho fundamental de los mismos y que conlleva la obligación de parte de los padres de elegir para ellos la mejor y la que más se les adapte como educadores cristianos ${ }^{45}$.

No podemos desarrollar el contenido de todas estas directrices del Catecismo, porque no tenemos espacio para ello. Pero están claras dos ideas, que la familia es educadora de la fe y que esta obligación de educar en la fe a los hijos es un deber y un derecho fundamental de los padres que son los primeros educadores de la fe de sus hijos.

\section{VIII}

\section{El Código de Derecho Canónico}

El Código de Derecho Canónico habla del derecho y del deber de los padres de educar a los hijos, en consecuencia corresponde a los padres cristianos en primer lugar procurar la educación cristiana de los hijos. En primer lugar al hablar de los derechos y obligaciones de los laicos dice: «Por haber transmitido la vida a sus hijos, los padres tienen el gravísimo deber y el derecho de educarles; por tanto, corresponde a los padres cristianos en primer lugar procurar la educación cristiana de sus hijos según la doctrina enseñada por la Iglesia.» (Can. 226+2).

En correlación perfecta con este canon en la parte correspondiente a la función de enseñar de la Iglesia, refiriéndose a la formación catequética afirma: «Antes que nadie los padres están obligados a formar a sus

\footnotetext{
43 Ibídem, n. 2226.

44 Ibídem, n. 2227.

45 Ibídem, n. 2229.
} 
hijos en la fe y en la práctica de la vida cristiana, mediante la palabra y el ejemplo; y tienen una obligación semejante quienes hacen las veces de padres y los padrinos.» (Ca. $774+2)$. En el párrafo anterior había insistido en la solicitud de todos por la catequesis; pero en este párrafo en consonancia con el Can. $226+2$ subraya de manera especial la obligación específica de los padres.

Hablando de los efectos del matrimonio vuelve a insistir sobre este deber de los padres: «Los padres tienen la obligación gravísima y el derecho primario de cuidar en la medida de sus fuerzas de la educación de la prole, tanto física, social y cultural, como moral y religiosa.» (Can. 1136).

El Can. $793+1$ después de indicar que los padres tienen el derecho y el deber de educar a sus hijos dice al final: «Tienen también el deber y el derecho de elegir aquellos medios e instituciones mediante los cuales pueden proveer mejor a la educación católica de los hijos.»

El Can. 776 recomienda al párroco que «promueva y fomente el deber de los padres en la catequesis familiar a la que se refiere el Can. $774+2 »$.

Estos son los cánones que directamente hablan de la familia como educadora de la fe. Pero indirectamente hablan también de la educación de la fe en la familia los cánones que hablan de la obligación de los padres de que se bauticen sus hijos en las primeras semanas (Can. $687+1)$; de la obligación que tienen los padres juntamente con los párrocos de que los hijos reciban la confirmación en tiempo oportuno (Can. 890) que los hijos se nutran cuanto antes de este divino alimento (la Eucaristía) (Can. 914).

Para que el artículo fuera completo deberíamos hacer una valoración de los documentos y de la mayor o menor importancia que puedan dar a la obligación de la educación en la fe. Pero el espacio no nos permite alargarnos más. Es más, ya lo hemos sobrepasado, aunque hemos procurado reducir lo más posible el número de los documentos y su contenido.

Hemos dejado de lado el Documento de Puebla, el de Santo Domingo y otros de Conferencias Episcopales que pueden encontrar citados en el libro Política de la familia, pp. 78-79, donde se habla del concepto de familia en los documentos eclesiásticos recientes. 